\title{
Adsorption of Acid Violet 17 onto Acid-Activated Pistachio Shell: Isotherm, Kinetic and Thermodynamic Studies
}

\author{
İlknur Şentürk* and Mazen Alzein \\ Department of Environmental Engineering, Faculty of Engineering, Sivas Cumhuriyet University, 58140, Sivas, Turkey \\ * Corresponding author: E-mail: ilknurg.senturk@gmail.com \\ Tel: +90 2191010/2445; Fax:+903462191165
}

Received: 04-12-2019

\begin{abstract}
The pistachio shell was modified using different chemical agents and utilized as an adsorbent for the adsorption of AV 17 dye in an aqueous solution. Maximum removal of $93.04 \%$ was obtained for pistachio shell activated with $10 \mathrm{~N} \mathrm{H}_{2} \mathrm{SO}_{4}$. The physicochemical properties of activated pistachio shell were characterized by $\mathrm{pH}_{\mathrm{pzc}}$, FTIR, BET, and SEM-EDX analysis. The results showed that the AV 17 adsorption capacity was positively correlated to the BET surface area. The best fit of kinetic data to pseudo-second-order kinetic was determined. The adsorption follows both the Langmuir and Temkin isotherms. The Langmuir adsorption capacity was determined to be $26.455 \mathrm{mg} / \mathrm{g}$ at the initial dye concentration of $160 \mathrm{mg} / \mathrm{L}$. The endothermic nature of adsorption was confirmed by the acquired thermodynamic data. Maximum desorption of $97.33 \%$ was achieved in $0.2 \mathrm{M} \mathrm{NaOH}$ for AAPS in the first cycle. This is very important for the economic use of the adsorbent. The findings demonstrate that activated pistachio shell may be a good alternative for color removal from industrial effluents.
\end{abstract}

Keywords: Acid Violet 17; adsorption; chemical activation; regeneration; Akaike's Information Criterion Test (AIC).

\section{Introduction}

Colored compounds containing pigments and dyes are commonly utilized in the food, textile, pharmaceutical, plastic, paper, leather, and cosmetics industries. These dyes form an aesthetically unacceptable color in the receiving waters. Furthermore, they cause serious environmental problems, carcinogenic and mutagenic effects on aquatic life due to their possible accumulation in the environment and high toxicity even at very high concentrations. ${ }^{1,2}$ Most of these dyes, acid dyes, in particular, are highly soluble in water because of the presence of sulphonic acid groups. Acidic dyes are commonly utilized to color products in the textile, leather, paper, printing and plastic industries.

It is necessary to treat such colored wastewaters to protect the environment and aquatic life. Due to the complex structures they have, it is quite difficult to discolor such wastewaters by conventional chemical and biological wastewater treatment methods (e.g. chemical flocculation, flotation, sedimentation, chemical oxidation and biological techniques). ${ }^{3}$ Because dyes are resistant to heat, light and microbial attacks due to their complex aromatic mo- lecular structure and synthetic origin. ${ }^{4}$ Therefore, alternative treatment methods should be considered. Adsorption is a widely preferred method in the treatment of dyed wastewaters due to the absence of hazardous by-product formation, simplicity of design, ease of use, non-sensitivity to toxic substances, the ability to treat dyes in a more concentrated form, being cheaper and more efficient than other methods, and flexibility in operation..$^{5}$ Activated carbon is among the most effective and most common adsorbents used for the adsorption process because of its effect and versatility. Nevertheless, commercially available activated carbon is quite expensive. Agricultural waste-based biomass can be used as an alternative to commercial activated carbon in the treatment of such dyed wastewaters with adsorption because the economic value of such agricultural waste materials is either absent or very little. It is observed that such adsorbents used in many studies provide effective results in color removal originating from dyes. ${ }^{1,2,5-7}$

Pistachio takes place among the most favorite tree nuts in the world. Pistachio trees naturally grow in dry and desert climate areas and represent native species to Iran, Syria, Greece, Turkey, the United States, China, Afghani- 
stan, Pakistan, and Turkmenistan. ${ }^{8}$ In 2016, the United States and Iran were the main producers of pistachio, and they accounted for $68 \%$ of the total world production of pistachio, which was 1.1 million tonnes. Turkey and China were determined to be the secondary producers of pistachio. Pistachio shell is generally used as a boiler fuel or sent to landfill as a waste. Thus, it will be useful to develop a new low-cost adsorbent from the pistachio shell, an agricultural waste. In this study, the acid-activated pistachio shell selected after different activation procedures was utilized as an adsorbent for the color removal of Acid Violet 17. The impacts of various operating parameters, including $\mathrm{pH}$, the dosage of adsorbent, time, initial dye concentration, temperature, ionic strength, and desorption, on the extent of adsorption in batch operation were examined, and optimal experimental conditions were determined. This study aimed to evaluate the adsorption capabilities of acid-activated pistachio shell in liquid media against Acid Violet 17 dye that is considered to be a model of acidic dye due to the presence of sulfonic groups in its structure.

\section{Material and Methods}

\section{1. Adsorbent}

Pistachio shell utilized in the present research was obtained from pistachios purchased from the local market. Firstly, the shells were washed with tap water and then washed several times with distilled water for the removal of dirt, dust and other impurities on their surface. At the end of washing, they were dried in the oven at $103-105^{\circ} \mathrm{C}$ until a constant weight was achieved. The dried shells were then milled and sieved. The particles $-1.0+0.71 \mathrm{~mm}$ (USA standard mesh chart) in size were used both as a raw material and in the preparation of acid-activated pistachio shell (activated carbon materials). All adsorbents were washed a few times using distilled water until the neutral $\mathrm{pH}$ of the filtrate was achieved. Afterward, the washed materials were dried at a temperature of $80{ }^{\circ} \mathrm{C}$ for a period of 24 hours in the oven.

\section{1. 1. Activation with $\mathrm{H}_{2} \mathrm{SO}_{4}$}

$25 \mathrm{~mL}$ of $1,5,10$ and $15 \mathrm{~N} \mathrm{H}_{2} \mathrm{SO}_{4}$ solution was taken, and $4 \mathrm{~g}$ of pistachio shell prepared for use in the experiments was added to it and mixed in a $250 \mathrm{~mL}$ Erlenmeyer flask. It was kept in a muffle furnace at a temperature of $353 \mathrm{~K}$ for a period of $24 \mathrm{~h}$ with the closed mouth of the Erlenmeyer flask. Following the treatment, cooling of all the samples to room temperature was performed; they were washed using distilled water until the neutral $\mathrm{pH}$ of the filtrate was achieved. The obtained activated carbon materials were dried in the oven at the temperature of $80{ }^{\circ} \mathrm{C} .{ }^{9}$ The adsorbent was placed in an airtight container for use in further studies. The obtained material was called as an acid-activated pistachio shell (AAPS).

\section{1. 2. Activation with $\mathrm{NaOH}$}

$4 \mathrm{~g}$ of pistachio shell ready for use in the experiments and $100 \mathrm{~mL}$ of $0.25 \mathrm{M} \mathrm{NaOH}$ solution were mixed at 300 rpm at $30{ }^{\circ} \mathrm{C}$ for 4 hours. To remove excess $\mathrm{NaOH}$ from the adsorbent's surface separated by the filter at the end of the process, it was washed a few times using distilled water until neutral $\mathrm{pH}$ was achieved and allowed to dry overnight in the oven at $80^{\circ} \mathrm{C} .{ }^{10}$ The adsorbent was placed in the airtight container for use in further studies.

\section{1. 3. Activation with CTAB}

$20 \mathrm{~g}$ of pistachio shell ready for use in the experiments and $200 \mathrm{~mL}$ of $4 \%$ of cetyl trimethyl ammonium bromide $(C T A B)$ solution were mixed at $150 \mathrm{rpm}$ at $30^{\circ} \mathrm{C}$ for 24 hours. The adsorbent separated by filtration at the end of the process was washed a few times using distilled water and allowed to dry in the oven at $70{ }^{\circ} \mathrm{C} .{ }^{11}$ The adsorbent was placed in the airtight container for use in further studies.

Furthermore, the adsorption capacity of the new adsorbent obtained by reactivating with 5 and $10 \mathrm{~N} \mathrm{H}_{2} \mathrm{SO}_{4}$ solution as described in section 2.1.1 of the adsorbent activated with $C T A B$ was investigated.

\section{2. Pollutant Dye}

C. I. Acid Violet $17\left(\mathrm{MF}, \mathrm{C}_{41} \mathrm{H}_{44} \mathrm{~N}_{3} \mathrm{NaO}_{6} \mathrm{~S}_{2}, \mathrm{MA}=\right.$ $761.93 \mathrm{~g} / \mathrm{mol}, \lambda_{\max }=542 \mathrm{~nm}$ ) dye is an anionic azo dye chosen as a model dye in the present research. The dye has a dark purple/dark violet color. The stock dye solution was prepared by weighing the dye and dissolving it in distilled water at the concentration of $1 \mathrm{~g} / \mathrm{L}$. Dilutions were made from the stock solution to the desired concentration and used in the studies. The chemical structure of Acid Violet 17 (AV 17) dye is presented in Fig. 1.

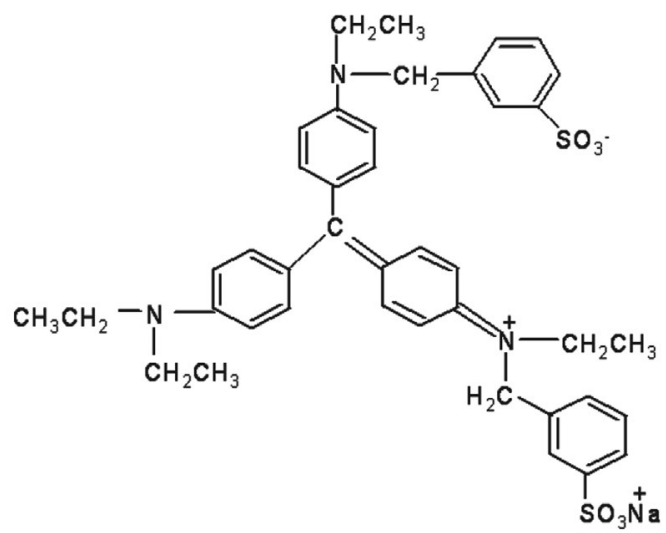

Fig. 1. Chemical Structure of Acid Violet $17 .^{2}$

\section{3. Instruments and Analysis Method}

A scanning electron microscope (SEM, Tescan Mira3 XMU) was utilized to determine the morphological 
properties and surface characteristics of the acid-activated pistachio shell adsorbent. Fourier transform infrared spectroscopy (FTIR, Bruker Tensor II) was employed to identify functional groups on the adsorbent. The specific surface area and micropore volume of the samples were measured using $\mathrm{N}_{2}$ adsorption-desorption (AUTOSORB 1C) at $-196^{\circ} \mathrm{C}$. Prior to adsorption, the samples were evacuated until a pressure of $66.6 \mathrm{~Pa}$ at room temperature was reached, then heated up to $50{ }^{\circ} \mathrm{C}$ and evacuated until a pressure of $1.3 \mathrm{~Pa}$ was reached. This condition was maintained overnight. The surface area, total pore volume and micropore volume were determined by multipoint BET, DFT (Density Functional Theory) and DR (Dubinin-Radushkevic), respectively. ${ }^{12}$ The solid addition method was employed for determining the point of zero charge $\left(\mathrm{pH}_{\mathrm{pzc}}\right)$ of the acid-activated pistachio shell. Preparation of a series of $0.1 \mathrm{M} \mathrm{KNO}_{3}$ solutions (50 $\mathrm{mL}$ each) was performed, and their $\mathrm{pH}$ was set in the interval of 1.0-12.0 as a result of adding $0.1 \mathrm{~N} \mathrm{HCl}$ and $\mathrm{NaOH}$. Addition of $0.1 \mathrm{~g}$ of the adsorbent was performed to every solution, and the suspensions were shaken, and the resulting solution was shaken for the period of $48 \mathrm{~h}$. The resulting $\mathrm{pH}$ of the solution was recorded, and a graph of the difference between the initial and final $\mathrm{pH}(\Delta \mathrm{pH})$ (Y-axis) was plotted against the initial $\mathrm{pH}$ (X-axis). The point of zero charge was obtained at the point of intersection of the mentioned curve. ${ }^{13}$

The concentration of the residual dye was analyzed by the UV-Visible spectrophotometer (Spectroquant Pharo 300, Merck) at a maximum wavelength of $542 \mathrm{~nm}$. The unknown AV 17 concentration was determined by using the standard curve obtained from the relationship between absorbance and concentration for AV 17. The correlation coefficient, $\mathrm{R}^{2}$ value, was determined to be 0.9997 .

\section{4. Adsorption Experiments}

Batch experiments were performed in a thermoshake incubator shaker (Gerhardt, Germany) operating at a constant speed of $125 \mathrm{rpm}$ with a working volume of 75 $\mathrm{mL}$ prepared at the desired conditions at $30^{\circ} \mathrm{C}$. The effects of various working parameters such as contact time, $\mathrm{pH}$, adsorbent dose, initial dye concentration, temperature, and ionic strength on AV 17 dye removal were investigat- ed. The study conditions of the adsorption experiments carried out under different experimental conditions are presented in Table 1.

Dye concentration in supernatant samples after agitating for $4 \mathrm{~h}$ was determined spectrophotometrically by monitoring the absorbance change of the dye solution that was separated from the adsorbent by centrifugation of the mixture at $5000 \mathrm{rpm}$ for $10 \mathrm{~min}$ for all studies except for determining the equilibrium time. The experiments were performed in duplicate, and the negative controls (without the sorbent added) were conducted at the same time for the purpose of ensuring sorption by the adsorbent material, not by the flask. During the analysis, the values of percentage removal and the amount of dye adsorbed were computed by utilizing the equations presented below:

$$
\begin{aligned}
& \text { Dye removal }(\%)=\frac{C_{i-} C_{e}}{C_{i}} 100 \\
& q_{e}=\frac{\left(C_{i}-C_{e}\right) V}{m}
\end{aligned}
$$

Where $q_{\mathrm{e}}$ denotes the adsorption capacity (the dye that is adsorbed onto the mass unit of the adsorbent, $\mathrm{mg} / \mathrm{g}), \mathrm{C}_{\mathrm{i}}$ and $\mathrm{C}_{\mathrm{e}}$ denote the initial dye concentration and the equilibrium dye concentration, respectively $(\mathrm{mg} / \mathrm{L})$, and $\mathrm{m}$ denotes the adsorbent dose $(\mathrm{g})$, and $\mathrm{V}$ denotes the volume of dye solution (L).

\section{5. Impact of Ionic Strength}

Generally, a higher salt concentration is determined in textile wastewater. Therefore, the impacts of ionic strength on the adsorption of dye must be investigated. ${ }^{14}$ The additional agents including salts and surfactants are commonly found in the textile industry wastewater. Adsorption is sensitive to the alteration in ionic strength. Two possible impacts of salts during wastewater treatment are as follows: (i) The equilibrium dye removal generally decreases (ii) Contrary to expectations, dye removal increases as the dye dissolution may be increased by the presence of the foreign salts. ${ }^{14}$ Hence, the impact of ionic strength on the adsorption efficiency of the adsorbent was investigated in the present research. The impact of ion strength

\begin{tabular}{|c|c|c|c|c|c|}
\hline $\begin{array}{c}\text { Process parameter } \\
\text { varied }\end{array}$ & $\begin{array}{l}\text { Initial dye } \\
\text { conc. }(\mathrm{mg} / \mathrm{L})\end{array}$ & $\begin{array}{l}\text { Dose } \\
(\mathrm{g} / \mathrm{L})\end{array}$ & $\begin{array}{l}\text { Contact } \\
\text { time }\end{array}$ & $\begin{array}{c}\text { Initial } \\
\text { pH }\end{array}$ & $\begin{array}{c}\text { Temperature } \\
\text { (K) }\end{array}$ \\
\hline Contact time & 40 & 10 & $0-360 \min$ & Solution $\mathrm{pH}$ & 303 \\
\hline Initial pH & 40 & 10 & $4 \mathrm{~h}$ & $2-12$ & 303 \\
\hline Initial dye concentration & $40,80,160$ & $4-20$ & $4 \mathrm{~h}$ & Solution $\mathrm{pH}$ & 303 \\
\hline Dose & $40,80,160$ & $4-20$ & $4 \mathrm{~h}$ & Solution $\mathrm{pH}$ & 303 \\
\hline Temperature & $20-400$ & 10 & $4 \mathrm{~h}$ & Solution $\mathrm{pH}$ & $303,313,323$ \\
\hline Ionic strength $(0.05-0.25 \mathrm{M})$ & 80 & 10 & $4 \mathrm{~h}$ & Solution $\mathrm{pH}$ & 313 \\
\hline
\end{tabular}

Table 1. Experimental conditions of the adsorption study. 
on the adsorption of dyes was tested with the addition of $\mathrm{NaCl}, \mathrm{SDS}$, and CTAB in the range of $0.05-0.25 \mathrm{M}$ to the solution.

\section{6. Desorption Studies}

Desorption studies help to explain adsorbate and adsorbent recovery and the adsorption mechanism. Since the regeneration of the adsorbent makes the treatment process economical, desorption studies were performed to regenerate the spent adsorbent. $75 \mathrm{~mL}$ of AV 17 solution with a concentration of $60 \mathrm{mg} / \mathrm{L}$ was taken and mixed with $1 \mathrm{~g}$ of fresh AAPS until equilibrium was reached $(4 \mathrm{~h})$. The AAPS adsorbent was then removed from the medium by centrifugation. $1 \mathrm{~g}$ of the dye-loaded adsorbent obtained $(0.1,0.2$, $0.4,0.8 \mathrm{M}$ ) was mixed separately with $100 \mathrm{~mL}$ of $\mathrm{HCl}$, $\mathrm{NaCl}, \mathrm{CH}_{3} \mathrm{COOH}, \mathrm{NaOH}$ desorption agents prepared at different concentrations $(0.1,0.2,0.4,0.8 \mathrm{M})$ and solvents (ethanol and distilled water) in the orbital mixer operating at $125 \mathrm{rpm}$. Desorption was performed in two different time periods, 24 and 48 hours. After this process, the solu- tion was separated by centrifugation, and the concentration of AV 17 that passed to the solution was determined spectrophotometrically. The percentage of the dye desorbed from the adsorbents is computed by means of the following formula:

$$
\begin{aligned}
& \% \text { Desorption }=(\text { Amount released to } \\
& \text { solution }(\mathrm{mg} / \mathrm{L}) / \text { Total adsorbed }(\mathrm{mg} / \mathrm{L}))^{*} 100
\end{aligned}
$$

Successive adsorption desorption studies were conducted in three cycles for the purpose of checking the reusability of the regenerated adsorbents. All the experiments, adsorption and desorption, were carried out in a batch setup in two replicates, and the mean values were acquired.

\section{Results and Discussion}

\section{1. Adsorbent Characterization}

An IR spectrum scan was performed in the wavelength interval of $400-4000 \mathrm{~cm}^{-1}$ to acquire information

a)

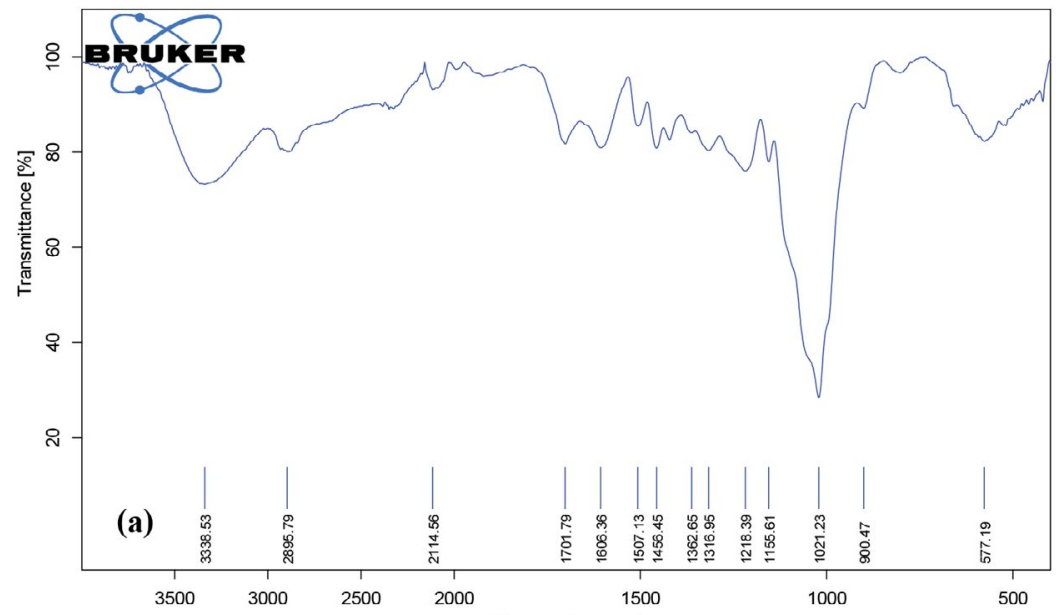

b)

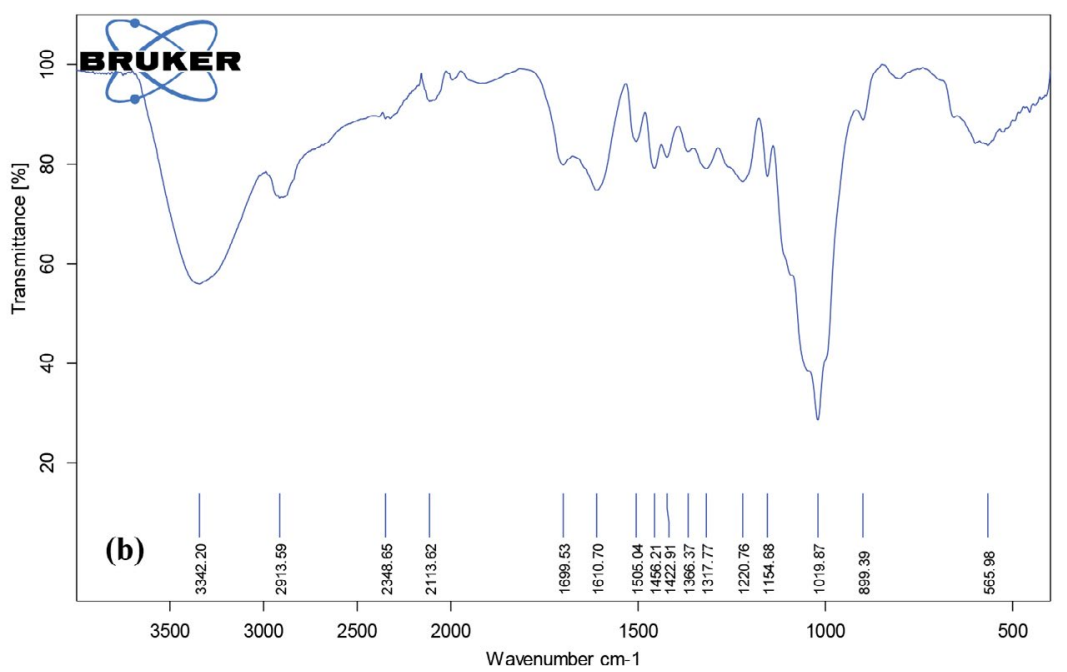

Fig. 2. FTIR spectra of (a) uncoated AAPS and (b) AV 17 coated AAPS. 
about the functional groups on the adsorbent's surface and its structure. Figure $2(a, b)$ demonstrate the FTIR spectra of acid-activated pistachio shell prior to and following its use in the adsorption of AV 17. The peak at a wavelength of $3338.53 \mathrm{~cm}^{-1}$ shows that the $\mathrm{O}-\mathrm{H}$ and $\mathrm{N}-\mathrm{N}$ (Amines) groups are present on AAPS, which is shifted to a wavelength of $3342.20 \mathrm{~cm}^{-1}$ following the dye adsorption. The peak at a wavelength of $2895.79 \mathrm{~cm}^{-1}$ originates from $\mathrm{C}-\mathrm{H}$ stretching vibrations of the alkane, which is shifted to a wavelength of $2913.59 \mathrm{~cm}^{-1}$ following the dye adsorption. The peak at a wavelength of $2114.56 \mathrm{~cm}^{-1}$ originates from $\mathrm{C} \equiv \mathrm{C}$ stretching, and the peak at a wavelength of $1701.79 \mathrm{~cm}^{-1}$ originates from $\mathrm{C}=\mathrm{O}$ (Aromatics) stretching. $\mathrm{O}-\mathrm{H}$ vibrations at 1606.36 $\mathrm{cm}^{-1}$ once again proved the presence of $\mathrm{H}_{2} \mathrm{O}$, which is shifted to a wavelength of $1610.7 \mathrm{~cm}^{-1}$ following the dye adsorption. The broad band at a wavelength of 1218.39 $\mathrm{cm}^{-1}$ confirms the presence of strong C-O stretching. ${ }^{2} \mathrm{~A}$ peak at a wavelength of $1021.23 \mathrm{~cm}^{-1}$ is obtained as a result of the C-N vibration of ester, which is shifted to a wavelength of $1019.87 \mathrm{~cm}^{-1}$ in the adsorbent's image following the dye adsorption. The peak that appeared at $577.19 \mathrm{~cm}^{-1}$ originates from the $\mathrm{C}-\mathrm{X}$ stretching vibrations of alkyl bromide, which is shifted to a wavelength of $565.98 \mathrm{~cm}^{-1}$ because of the C-X stretching vibrations of alkyl chloride after the adsorption of the dye. Before (Fig. 2a) and after (Fig. 2b) adsorption, the FTIR spectra of the adsorbent showed similar features, and only peak shifts and changes in peak intensity were observed. Only two new peaks, the one at a wavelength of $2348.65 \mathrm{~cm}^{-1}$ attributed to the $\mathrm{C} \equiv \mathrm{N}$ stretch of alkyne and the other one at a wavelength of $1422.91 \mathrm{~cm}^{-1}$ attributed to the C-H stretch of AV 17 dye in Fig. $2 \mathrm{~b}$ also proved the adsorption of the dye.

The surface texture and morphological characteristics of the $\mathrm{H}_{2} \mathrm{SO}_{4}$ activated pistachio shell used as an adsorbent were viewed by a scanning electron microscope (SEM). Figure 3(a,b) demonstrate SEM images of acid-activated pistachio shell prior to and following its use in the Acid Violet 17 adsorption. The images presented in Fig. 3a for the adsorbent before adsorption demonstrate that the adsorbent's porous and rough structure was effective in the dye adsorption. Furthermore, the adsorbent's surface appears to be uneven and irregular and have cavities which may promote the interaction of the dye ions with the surface of the adsorbent causing good dye adsorption. An alteration in the rough surfaces of the adsorbent was determined following the usage in the adsorption proving the suggested mechanisms of good dye interactions causing the dye adsorption on the acid-activated pistachio shell.

Energy dispersive X-ray analysis, abbreviated as EDX, represents a common tool for accompanying SEM as well as TEM. The mentioned technique is usually employed for determining relative abundance, the composition of elements, and distribution in a sample. ${ }^{15}$ Using EDX, the composition of the acid-activated pistachio shell was studied. Fig. 4 shows that carbon, oxygen, chlorine, sulphur, and bromine atoms are the main chemical elements on the material's surface.

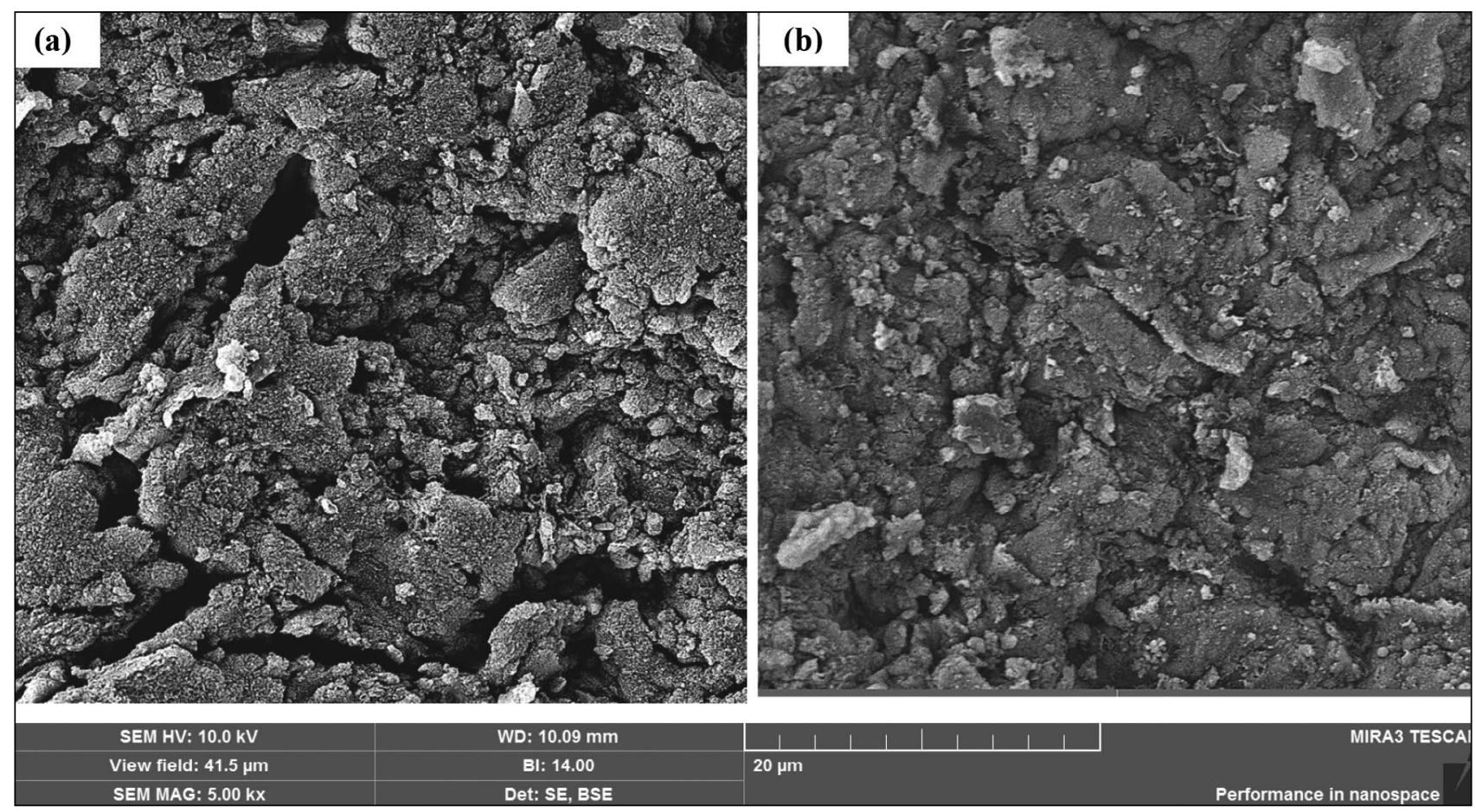

Fig. 3. SEM photograph of (a) uncoated AAPS and (b) AV 17 coated AAPS. 

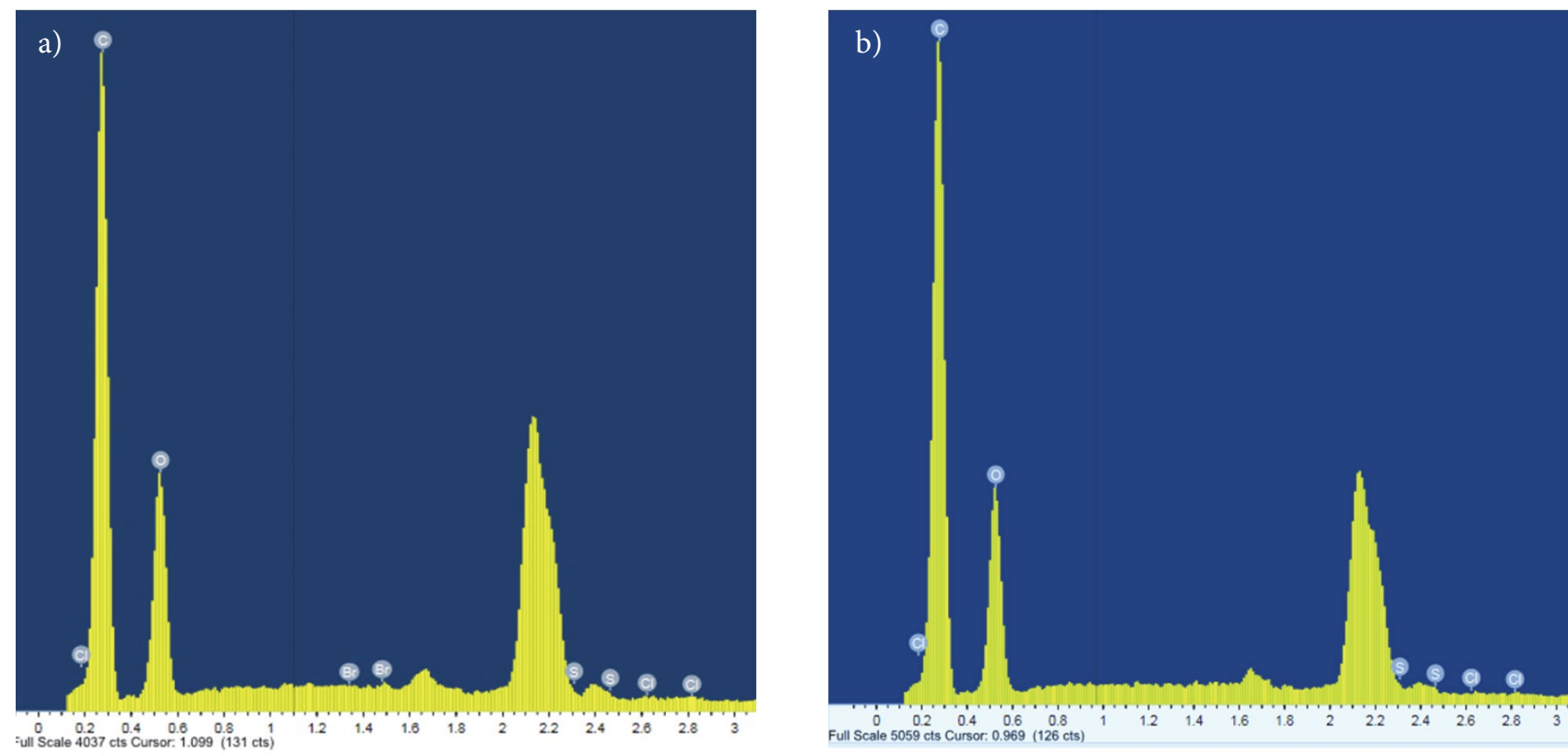

Fig. 4. EDX spectra of AAPS (a) prior to adsorption and (b) following adsorption.

The nitrogen adsorption-desorption isotherms of the natural pistachio shell and acid activated pistachio shell are shown in Fig. 5. The adsorption-desorption isotherms of samples are of type III (BET classification) according to the IUPAC classification, ${ }^{16}$ suggesting that samples contain micro- and mesoporous that allow the formation of multiple adsorbent layers with increasing $\mathrm{P} / \mathrm{P}^{\circ}$. The acid activated pistachio shells were found to have high surface area and mesopore volumes as compared with natural pistachio shells as seen in Table 2. With the acid activation of pistachio shell, some of the existing bonds might be broken and new bonds may be formed. It might be due to the formation of micropores. As a result, the surface area of activated pistachio shell increased to $55.8 \mathrm{~m}^{2} / \mathrm{g}$ from $15.3 \mathrm{~m}^{2} / \mathrm{g}$.

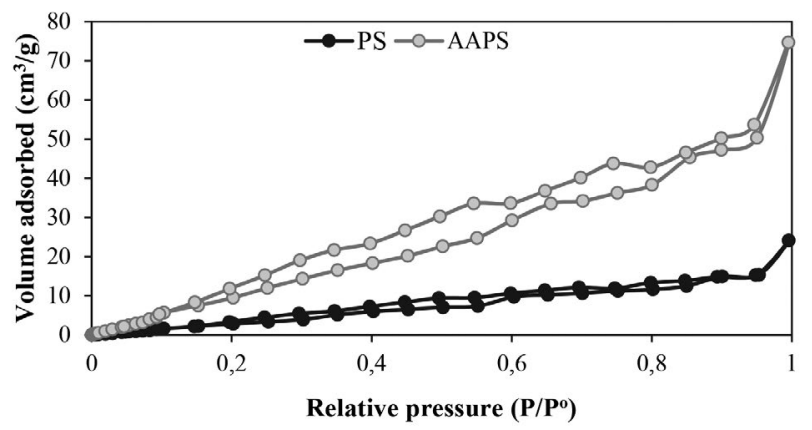

Fig. 5. The nitrogen adsorption-desorption isotherm of PS and AAPS.

The point of zero charge, in physical chemistry, is a concept used to understand the mechanism of adsorption better. As shown in Fig. 6, the point of zero charge, $\mathrm{pH}_{\mathrm{pzc}}$,
Table 2. The surface area and pore characteristics of natural (PS) and acid activated pistachio shell (AAPS).

\begin{tabular}{lcc}
\hline & PS & AAPS \\
\hline $\mathrm{S}_{\text {BET }}{ }^{\mathrm{a}}\left(\mathrm{m}^{2} / \mathrm{g}\right)$ & 15.3 & 55.8 \\
$\mathrm{~V}_{\text {Total }}{ }^{\mathrm{b}}\left(\mathrm{cm}^{3} / \mathrm{g}\right)$ & 0.02 & 0.08 \\
$\mathrm{~V}_{\text {micro }}{ }^{c}\left(\mathrm{~cm}^{3} / \mathrm{g}\right)$ & 0.006 & 0.010 \\
$\mathrm{D}_{\mathrm{p}}{ }^{\mathrm{d}}(\AA)$ & 31 & 28 \\
\hline
\end{tabular}

${ }^{\mathrm{a}}$ Multipoint BET method; ${ }^{\mathrm{b}}$ Volume adsorbed at $\mathrm{P} / \mathrm{P}^{\mathrm{o}}=0.99$; ${ }^{\mathrm{c}} \mathrm{Mi}-$ cropore volume calculated by DR method; ${ }^{\mathrm{d}}$ Average pore diameter determined by DFT

is 9.6 whereas the adsorption of cations is preferred when $\mathrm{pH}>\mathrm{pH}_{\mathrm{pzc}}$, otherwise, anions are adsorbed. ${ }^{17}$ According to the results, since $\mathrm{pH}<\mathrm{pH}_{\mathrm{pzc}}, \mathrm{AV} 17$, which is an anionic dye, is preferred by the adsorbent.

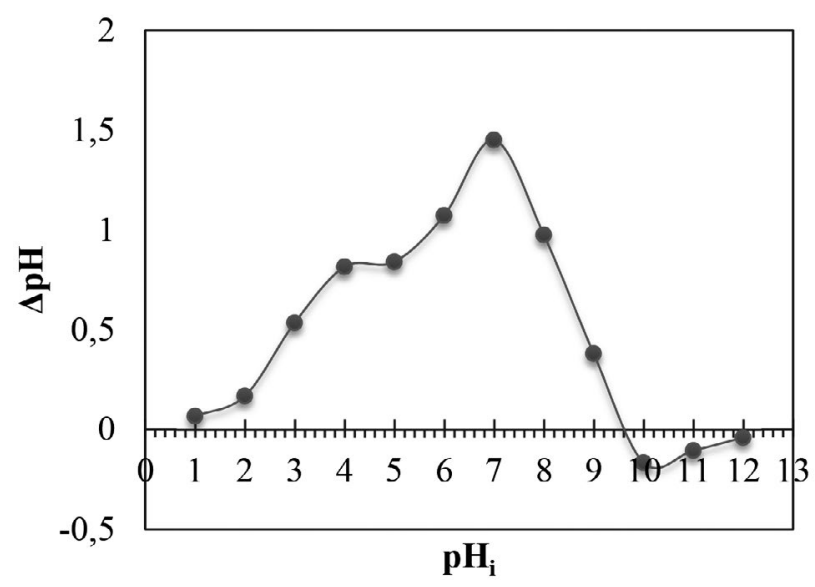

Fig. 6. $\mathrm{pH}_{\mathrm{pzc}}$ of AAPS. 


\section{2. Batch Studies}

\section{2. 1. Impact of Activation Procedures on Adsorption Efficiency}

In the study, the natural pistachio shell, pistachio shell activated with $0.25 \mathrm{~N} \mathrm{NaOH}$ solution, pistachio shell activated with 1-5-10 and $15 \mathrm{~N} \mathrm{H}_{2} \mathrm{SO}_{4}$, pistachio shell activated with $\mathrm{CTAB}$, and pistachio shells that were again subjected to a chemical activation process with 5 and $10 \mathrm{~N}$ $\mathrm{H}_{2} \mathrm{SO}_{4}$ solutions after activation with CTAB were evaluated in terms of their adsorption efficiency. $75 \mathrm{~mL}$ of 40 $\mathrm{mg} / \mathrm{L}$ AV 17 solution was taken in each Erlenmeyer flask prepared, and $0.75 \mathrm{~g}$ of the adsorbent was added to it. The prepared mixture was subjected to adsorption at a stirring rate of $125 \mathrm{rpm}$ at $30^{\circ} \mathrm{C}$ for 24 hours at the natural $\mathrm{pH}$ of the dye solution. At the end of 24 hours, samples taken from each Erlenmeyer flask were analyzed, and the adsorbent which could be used most efficiently for the removal of AV 17 dye was determined. The results of the study are presented in Table 3.

Activated pistachio shells and natural pistachio shell were used as adsorbent in the adsorption process for $\mathrm{AV}$ 17 dye removal. As a result of the studies, it was observed that efficiency of $24.35 \%$ was obtained with the natural pistachio shell and activation of the adsorbent was effective in increasing the efficiency. The best results were obtained after activation with $\mathrm{H}_{2} \mathrm{SO}_{4}$. The efficiency of AV 17 removal after activation with CTAB was $79.5 \%$. In order to increase this efficiency, the adsorbent activated with $\mathrm{CTAB}$ was also reactivated with $5 \mathrm{~N}$ and $10 \mathrm{~N} \mathrm{H}_{2} \mathrm{SO}_{4}$, and the removal efficiency of the new material was analyzed, and $81.4 \%$ and $93.36 \%$ efficiency was obtained, respectively.

The general reaction scheme of the distribution of hydronium ion of $\mathrm{H}_{2} \mathrm{SO}_{4}$ in water is: ${ }^{18}$

$$
\mathrm{H}_{2} \mathrm{SO}_{4}+\mathrm{H}_{2} \mathrm{O} \leftrightarrow \mathrm{HSO}_{4}^{-}+\mathrm{H}_{3} \mathrm{O}^{+}
$$$$
\mathrm{HSO}_{4}^{-}+\mathrm{H}_{2} \mathrm{O} \leftrightarrow \mathrm{SO}_{4}{ }^{-}+\mathrm{H}_{3} \mathrm{O}^{+}
$$

As we seen from reaction, the $\mathrm{HSO}_{4}{ }^{-}$and $\mathrm{SO}_{4}=$ are week bases and can be replaced by the AV 17 ions which is a stronger base. Adsorption efficiency increased with increasing $\mathrm{H}_{2} \mathrm{SO}_{4}$ activity on adsorbent. Since the same effi-
Table 3. AV 17 removal efficiency and adsorption capacity after activation.

\begin{tabular}{lcc}
\hline Activation procedures & (\%) & $\mathbf{q}_{\mathbf{e}}(\mathbf{m g} / \mathbf{g})$ \\
\hline Natural pistachio shell & 24.35 & 1.004 \\
Activation with $0.25 \mathrm{~N} \mathrm{NaOH}$ & 67.81 & 2.797 \\
Activation with $1 \mathrm{~N} \mathrm{H}_{2} \mathrm{SO}_{4}$ & 72.99 & 3.011 \\
Activation with $5 \mathrm{~N} \mathrm{H}_{2} \mathrm{SO}_{4}$ & 79.43 & 3.276 \\
Activation with $10 \mathrm{~N} \mathrm{H}_{2} \mathrm{SO}_{4}$ & 93.04 & 3.838 \\
Activation with $15 \mathrm{~N} \mathrm{H}_{2} \mathrm{SO}_{4}$ & 94.23 & 3.887 \\
Activation with CTAB & 79.49 & 3.279 \\
Reactivating with $5 \mathrm{~N} \mathrm{H}_{2} \mathrm{SO}_{4}$ & 81.40 & 3.361 \\
of the adsorbent activated with CTAB & & \\
Reactivating with $10 \mathrm{~N} \mathrm{H}_{2} \mathrm{SO}_{4}$ & 93.36 & 3.855 \\
of the adsorbent activated with CTAB & & \\
\hline
\end{tabular}

ciency was obtained after the activation of the adsorbent with $10 \mathrm{~N} \mathrm{H}_{2} \mathrm{SO}_{4}$, it was decided that it would be appropriate to continue working with pistachio shells activated with $10 \mathrm{~N} \mathrm{H}_{2} \mathrm{SO}_{4}$ in future studies.

Several chemical activating agents are used by researchers such as zinc chloride $\left(\mathrm{ZnCl}_{2}\right)$, phosphoric acid $\left(\mathrm{H}_{3} \mathrm{PO}_{4}\right)$, potassium hydroxide $(\mathrm{KOH})$, calcium chloride $\left(\mathrm{CaCl}_{2}\right)$, sulfuric acid $\left(\mathrm{H}_{2} \mathrm{SO}_{4}\right)$, sodium hydroxide $(\mathrm{NaOH})$, hydrochloric acid $(\mathrm{HCl})$, nitric acid etc. ${ }^{19}$ This activating agents are used to modify adsorbent to increase its efficiency for adsorption.

Modification with acidic reagents will increase the hydrogen ion content $(\mathrm{H}+)$ causing increased positive charge on the material surface. This situation leading to enhanced AV 17 removal which is negatively charged. Inorganic (stronger acid) acids $\left(\mathrm{HCl}, \mathrm{H}_{2} \mathrm{SO}_{4}\right.$ and $\mathrm{HNO}_{3}$ ) treatment show that the addition of $\mathrm{H}_{2} \mathrm{SO}_{4}$ increases adsorbent yield, surface area and porosity. ${ }^{20}$ The same results were also encountered in our study.

\section{2. 2. Impact of Contact Time (Kinetics Study)}

The effect of contact time on the removal of AV 17 by adsorption was studied under the conditions given in Ta-

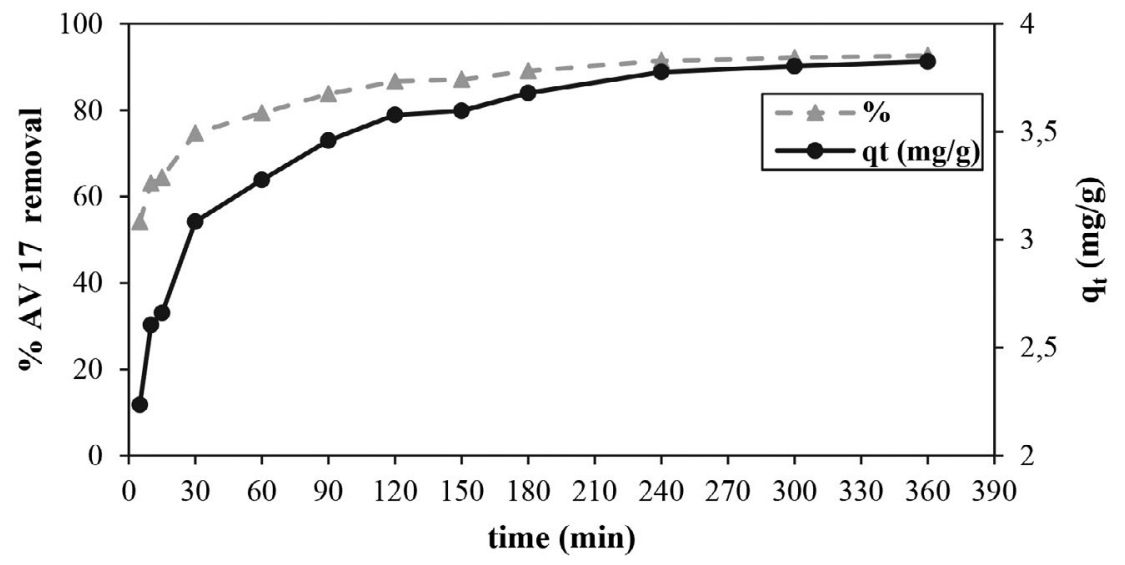

Fig. 7. Impact of agitation time on the adsorption of AV 17 by AAPS. 
ble 1, and the relevant data are given in Fig. 7. It is observed from Fig. 7 that the process was initially very rapid and $54 \%$ color removal was obtained in the first 5 minutes. $92 \%$ removal was achieved at the end of 4 hours. The relative increase in the extent of dye removal following 240 min of contact time was found to be insignificant. This is probably because of the accumulation of dyes on the available adsorption sites on the adsorbent material. Hence, 240 min contact time is fixed as the optimal contact time.

\section{2. 2. 1. Kinetics of Adsorption}

The adsorptive uptake of dye at various time intervals was analyzed for the purpose of determining the kinetics of adsorption. The data acquired from adsorption kinetic studies were assessed with the help of various kinetic models selected for the purpose of investigating the adsorption dynamics that control the sorption process, including diffusion control, chemical reaction and mass transfer. The kinetic parameters that can help in predicting the adsorption rate provide significant information to design and model the adsorption process. ${ }^{21,22}$ Thus, models including pseudo-first-order, pseudo-second-order, intra-particle diffusion, and Elovich, which are commonly utilized for the adsorption of pollutants from liquid solutions, were implemented for the data obtained from experimental studies to determine the adsorption kinetics. A summary of the models and constants and the determination coefficients for the linear regression plots of AV 17 dye are presented in Table 4. As is seen in Table 4, higher $R^{2}$ values were acquired for pseudo-second-order compared to the other adsorption rate models, which demonstrated that the pseudo-second-order rate could describe the adsorption rates of AV 17 onto the AAPS adsorbent more appropriately in comparison with the other models because of its high correlation coefficient $\left(\mathrm{R}^{2}=0.9995\right)$.

The $\Delta q$ (the standard deviation between the experimental and computed adsorption capacities) values in Table 4 also prove the perfect fit of experimental results to the pseudo-second-order model. However, the pseudo-second-order kinetic model cannot describe the diffusion mechanism alone. The transfer of the dissolved matter in an adsorption system can be characterized by intra-parti- cle diffusion or by both models. ${ }^{23}$ Therefore, the intra-particle diffusion model was also implemented for the data obtained from kinetic studies for the purpose of explaining the diffusion mechanism. However, the low $\mathrm{R}^{2}$ value obtained demonstrated that the adsorption process alone does not depend on the intra-particle diffusion model and that the diffusion mechanism can be characterized by both models together.

When $C$ is zero, the intra-particle diffusion represents the sole rate-limiting step, and with an increase in the value of $C$, the contribution of surface adsorption increases. The plots were determined to be not linear in the whole time range. However, it was possible to separate them into two-three linear regions, indicating the presence of multiple stages to the adsorption process. ${ }^{21}$ The $R^{2}$ values are $<0.9$ (Table 4), which demonstrates that intra-particle diffusion cannot describe the adsorption of AV 17 on AAPS, and due to the fact that the mentioned lines do not pass through the origin, it is possible to conclude that intra-particle diffusion does not represent the sole rate controlling step.

\section{2. 3. Impact of Initial $\mathrm{pH}$}

The $\mathrm{pH}$ value of the solution is very significant in the process of adsorption since it affects the surface loads of dye and adsorbent materials. The impact of the initial $\mathrm{pH}$ of the dye solution on the amount of adsorbed AV 17 dye was investigated by changing the initial $\mathrm{pH}$ value between 2-12 while the other parameters were kept constant (Table 1). Dilute $\mathrm{HCl}$ or $\mathrm{NaOH}(0.1 \mathrm{M})$ solutions were utilized to adjust $\mathrm{pH}$. The results are shown in Fig. 8. After $\mathrm{pH} 6$, some decrease $(2 \%)$ was observed in the removal efficiency. The change in adsorption capacity was also slight. The $\mathrm{pH}$ of the dye solution is 6.1. In accordance with the findings presented above, a $\mathrm{pH}$ of 6.1 was selected as the optimum $\mathrm{pH}$ to remove $\mathrm{AV} 17$ in the future experiments.

Due to the presence of the sulphonate group, AV 17 carries a negative charge in the aquatic solution. Therefore, for effective dye removal, the adsorbent surface must have positive charges. ${ }^{5}$ Since the AAPS surface has negative charges, it is observed that the removal efficiency increases

Table 4. Modeling of adsorption kinetics.

\begin{tabular}{|c|c|c|c|c|}
\hline Model & Pseudo-first-order equation & $\begin{array}{l}\text { Pseudo-second-order } \\
\text { equation }\end{array}$ & Weber-Morris & Elovich \\
\hline Equation & $\ln \left(q_{e}-q_{t}\right)=\ln q_{e}-k_{1} t^{24}$ & $t / q_{t}=\left(1 / k_{2} q_{e}^{2}\right)+t / q_{e}{ }^{24}$ & $q_{t}=k_{d} t^{1 / 2}+C^{25}$ & $q_{t}=\beta \ln (\alpha)+\beta \ln t^{26}$ \\
\hline Plot & $\ln \left(q_{e}-q_{t}\right)$ vs. $t$ & $\left(t / q_{t}\right)$ vs. $t$ & $q_{t} v$ s. $t^{1 / 2}$ & $q_{t} v \mathrm{~s} . \ln t$ \\
\hline Fitted model & $\ln (\mathrm{qe}-\mathrm{qt})=-0.0146 \mathrm{t}+0.2768$ & $\mathrm{t} / \mathrm{qt}=2.091+0.2573 \mathrm{t}$ & $\mathrm{q}_{\mathrm{t}}=0.0883 \mathrm{t}^{1 / 2}+2.4123$ & $\mathrm{q}_{\mathrm{t}}=0.3766 \ln (\alpha)+0.3766 \ln \mathrm{t}$ \\
\hline$R^{2}$ & 0.9762 & 0.9995 & 0.8698 & 0.9868 \\
\hline Constant & $\mathrm{k}_{1}=0.0146 \mathrm{dk}^{-1}$ & $\mathrm{k}_{2}=0.0318 \mathrm{mg} /(\mathrm{g} \mathrm{dk})$ & $\mathrm{k}_{\mathrm{d}}=0.0883 \mathrm{mg} / \mathrm{g} \mathrm{dk}^{1 / 2}$ & $\begin{array}{l}\alpha=93.344 \mathrm{mg} / \mathrm{g} \mathrm{dk} \\
\beta=0.3766 \mathrm{~g} / \mathrm{mg}\end{array}$ \\
\hline$q_{e},\left(q_{e, c a l}\right)$ & $1.319 \mathrm{mg} / \mathrm{g}$ & $3.886 \mathrm{mg} / \mathrm{g}$ & - & - \\
\hline$q_{e},\left(q_{e, \exp }\right)$ & $3.776 \mathrm{mg} / \mathrm{g}$ & $3.776 \mathrm{mg} / \mathrm{g}$ & - & - \\
\hline & 1.737 & 0.077 & & \\
\hline
\end{tabular}


when the $\mathrm{pH}$ value of the solution is in the range of 5-6 because $\mathrm{pH}$ affects the surface characteristics of the adsorbent and dissociation of the dye molecules. The adsorbent's zero-point charge $\left(\mathrm{pH}_{\mathrm{zpc}}\right)$ was found to be 9.6. Fig. 8 shows that the maximum dye removal is at $\mathrm{pH}$ 6, i.e. $\mathrm{pH}$ $<\mathrm{pH}_{\mathrm{zpc}}$. In this case, because the positive charge density on the AAPS increases, the adsorption of an anionic dye AV17 also increases. If the exact opposite situation occurred, i.e. $\mathrm{pH}>\mathrm{pH}_{\mathrm{zp}}$, the adsorption of anionic dyes on AAPS would not be possible due to the propulsive electrostatic force caused by the same charges, since the negative charge density on the adsorbent would increase.

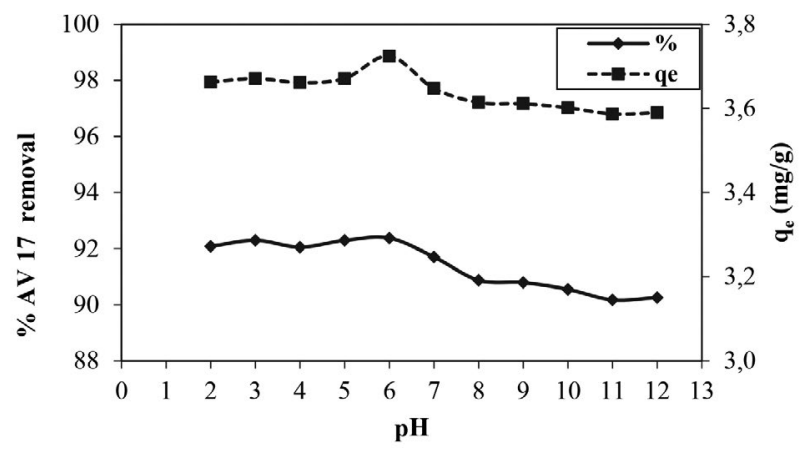

Fig. 8. Impact of $\mathrm{pH}$ on the removal of AV 17 onto AAPS.

\section{2. 4. Impact of Dye Concentration and Adsorbent Dosage}

Since the adsorbent determines the adsorbent capacity for the given initial concentration, the adsorbent dosage is a significant parameter. The impact of AAPS quantity on the removal of AV 17 was examined, and the findings are presented in Fig. 9. As stated, the amount adsorbed in the unit mass of the adsorbent decreased with an increase in the adsorbent dosage. A decrease in $\mathrm{q}_{\mathrm{e}}$ with the increasing dose may be caused by the overlapping of adsorption sites as a result of overloading the adsorbent particles. Likewise, as the concentration of the dye solution increased, the amount of the adsorbed dye also increased. In the adsorbent dosage of $4 \mathrm{~g} / \mathrm{L}$, the adsorption capacity was $8.173 \mathrm{mg} / \mathrm{g}$ at the dye concentration of $40 \mathrm{mg} / \mathrm{L}$, while this

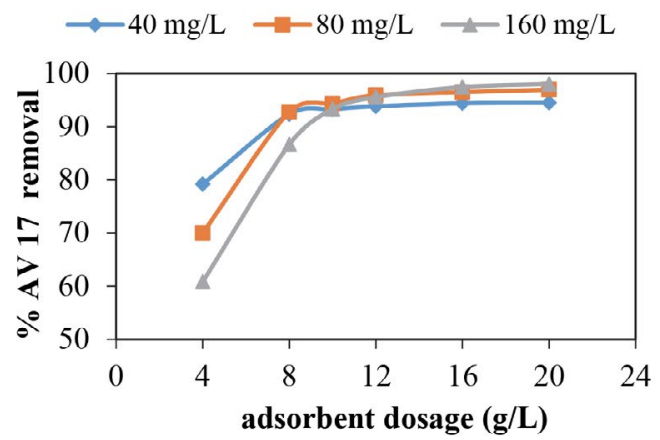

Fig. 9. Impact of adsorbent dosage on the adsorption of AV 17 by AAPS. value became $23.551 \mathrm{mg} / \mathrm{g}$ at the concentration of 160 $\mathrm{mg} / \mathrm{L}$. Garg et al. obtained similar results in 2003. The dye removal data obtained at three different concentrations are presented in Fig. 9. This figure indicates that the AV 17 removal increased up to a $10 \mathrm{~g} / \mathrm{L}$ adsorbent dosage and then reached saturation. The increase in dye removal with a certain increase in the adsorbent dosage may be related to the availability of more adsorption sites and increased surface area. ${ }^{9}$

The dye removal was not affected by a further increase in the adsorbent dose. Thus, in other parameter experiments, the adsorbent amount of $10.0 \mathrm{~g} / \mathrm{L}$ was selected. It was determined that, in case of providing sufficient adsorption sites, the removal of AV 17 remains independent of the amount of the adsorbent for AAPS.

The initial dye concentration represents another significant parameter that may influence the process of adsorption. Fig. 9 also presents the findings with regard to removal efficiency versus initial dye concentration. As can be seen in Fig. 9, a slight decrease was observed in AV 17 removal at the initial dosage of $4 \mathrm{~g} / \mathrm{L}$ from approximately $80 \%$ at a $40 \mathrm{mg} / \mathrm{L}$ concentration to $60.84 \%$ with an increase in the concentration to $160 \mathrm{mg} / \mathrm{L}$. However, when the initial dosage was $10.0 \mathrm{~g} / \mathrm{L}$, the removal efficiency was constant at values higher than $93 \%$ in the whole range of the studied dye concentrations, which demonstrated that its adsorption was independent of the initial concentration.

\section{2. 4. 1. Adsorption Isotherms}

The adsorption isotherm is defined as the equilibrium relation between the quantity of adsorbate per unit of adsorbent $\left(q_{\mathrm{e}}\right)$ and its equilibrium solution concentration $\left(C_{\mathrm{e}}\right)$ at a constant temperature. ${ }^{27}$ It is crucial to develop a suitable isotherm model for adsorption for designing and optimizing the processes of adsorption. ${ }^{28}$ Isotherms are frequently utilized for the purpose of describing the equilibrium behavior of the adsorption process. Equilibrium sorption is generally defined by the isotherm equation characterized by some parameters expressing the interest of the adsorbent in the substance to be adsorbed and the surface properties of the sorbent. ${ }^{29}$

The equilibrium isotherm of a certain adsorbent demonstrates its adsorptive properties and is crucial for

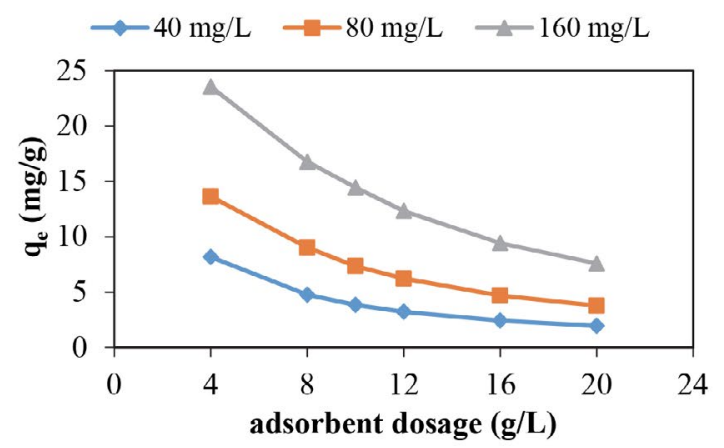




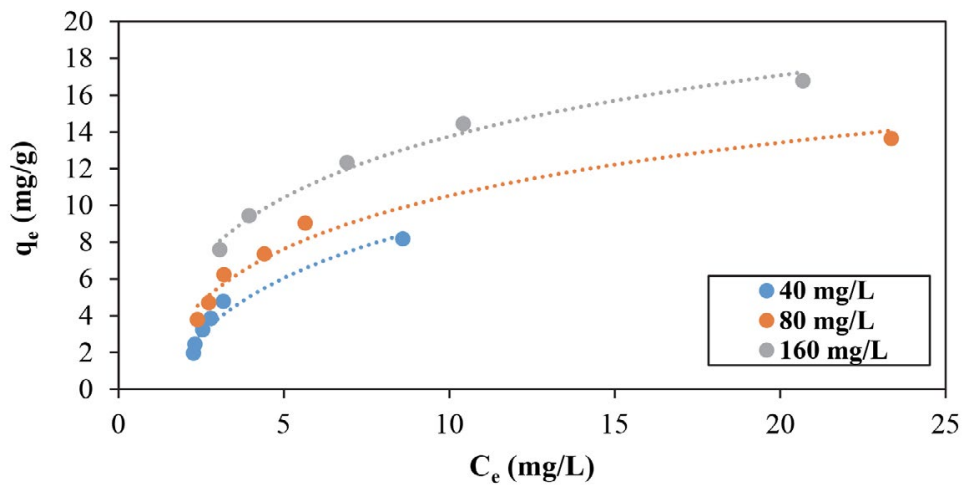

Fig. 10. Adsorption isotherm of Acid Violet 17 at different adsorbent dosages.

designing the adsorption process. ${ }^{30}$ Experiments to estimate the adsorption isotherms of AV 17 onto AAPS were carried out with the addition of different quantities of AAPS, in the range of $4-20 \mathrm{~g} / \mathrm{L}$, to a series of Erlenmeyer flasks, each of which contained dye solution at a concentration of $160 \mathrm{mg} / \mathrm{L}$. The adsorption isotherms were fitted using a few two- and three-parameter isotherms. The two-parameter models are the Langmuir, Freundlich, Dubinin-Radushkevich (D-R), and Temkin isotherms, whereas the three-parameter model is the Redlich and Peterson (R-D) isotherm. Fig. 10 exhibits the adsorption curves of $40,80,160 \mathrm{mg} / \mathrm{L} \mathrm{AV} 17$ concentration on the different adsorbent dosage $(4-20 \mathrm{~g} / \mathrm{L})$.

In batch adsorption studies, it is common to fit the equilibrium uptake data to a number of isotherms, afterward to utilize $\mathrm{R}^{2}$ in order to compare the goodness of fit and choose the best isotherm model. If it is assumed that the best isotherm is determined, findings on the homogeneity of the adsorbent's surface and the adsorption mechanism are generally presented. Nevertheless, a common drawback of certain studies is the use of $\mathrm{R}^{2}$ for the purpose of comparing two, three, and four-parameter isotherms. ${ }^{31}$

Akaike's information criterion (AIC) ${ }^{32}$ is a statistical method that is well-established and can be employed for a comparison of models. Information theory and maximum likelihood theory constitute its basis, and therefore, it identifies which model has a higher probability of being correct and quantifies to what extent it is more probable. For a small sample size, AIC is computed for every model using Eq. (3):

$$
\mathrm{AIC}=\mathrm{N} \ln \left(\frac{S S E}{N}\right)+2 \mathrm{~N}_{\mathrm{p}}+\frac{2 N_{P}\left(N_{P}+1\right)}{N-N_{P}-1}
$$

where $\mathrm{N}$ represents the number of data points, $\mathrm{N}_{\mathrm{P}}$ represents the number of parameters in the model, and SSE represents the sum of the error squares.

A minimization process was applied for the solution of isotherms and kinetic equations as a result of the minimization of the sum of error squared (SSE) between the values predicted and the experimental data. ${ }^{32}$
The errors represent the difference between the value observed and the value that the model has predicted (Eq. 4):

$$
\mathrm{SSE}=\sqrt{\sum\left(q_{\exp -} q_{\text {cal }}\right)^{2} / N}
$$

where the subscripts "exp" and "cal" denote the experimental and calculated $q$ values, respectively and $N$ denotes the number of measurements.

It is possible to compare AIC values by utilizing the evidence ratio which is found as in (Eq. 5):

$$
\text { Evidence ratio }=\frac{1}{e^{-0,54}}
$$

where $\Delta$ represents the absolute value of the difference in AIC between the two models. ${ }^{31}$

Table 5 presents the all isotherm parameters and the results of nonlinear regression. The present research reached a conclusion, based on $R^{2}$ comparison, that the $\mathrm{D}$ - $\mathrm{R}$ isotherm had a smaller $R^{2}$ value compared to the other models. The adsorption isotherm fits the Langmuir and Temkin models well. Nevertheless, it is considered to be more suitable to compare the goodness of fit to the Langmuir and Temkin isotherms using AIC. Therefore, AIC values were computed for the Langmuir $(-2.908)$ and Temkin (-3.664) isotherms, respectively. A smaller AIC value indicates that there is a higher probability that the Temkin isotherm will be a better fit. The evidence ratio of 1.459 suggests that there is a 1.459 times higher probability that the Temkin isotherm will be the correct model in comparison with the Langmuir isotherm.

Furthermore, it is possible to determine the parameters of every isotherm equation as a result of minimizing the SSE. The best-fit model is required to have a minimum SSE value. Thus, it is possible to acquire the model in question as a result of comparing the SSE of every model. Table 5 presents a comparison of the SSE values. As a result of a comparison of the SSE of the Langmuir and Temkin isotherm models, the Temkin isotherm appears to be the best fit.

In accordance with the Langmuir model, the adsorption of AV 17 was the monolayer adsorption and occurred 
Table 5. Equilibrium modeling for the adsorption of AV 17 by the AAPS.

\begin{tabular}{|c|c|c|}
\hline Isotherm & Unit & Information \\
\hline $\begin{array}{l}\text { Langmuir model } \\
\text { Plot } \\
\text { Fitted model } \\
q_{\max } \\
k_{L} \\
R^{2} \\
R_{L}=1 / 1+\left(k_{L} C_{i}\right) \\
\text { SSE } \\
\text { AIC }\end{array}$ & $\begin{array}{l}- \\
- \\
{[\mathrm{mg} / \mathrm{g}]} \\
{\left[\mathrm{dm}^{3} / \mathrm{mg}\right]} \\
-\end{array}$ & $\begin{array}{l}\mathrm{C}_{\mathrm{e}} / \mathrm{q}_{\mathrm{e}}=1 / \mathrm{k}_{\mathrm{L}} \mathrm{q}_{\max }+\mathrm{C}_{\mathrm{e}} / \mathrm{q}_{\max } 24 \\
\left(\mathrm{C}_{\mathrm{e}} / \mathrm{q}_{\mathrm{e}}\right) v \mathrm{~s} . \mathrm{C}_{\mathrm{e}} \\
\mathrm{C}_{\mathrm{e}} / \mathrm{q}_{\mathrm{e}}=0.319+0.0378 \mathrm{C}_{\mathrm{e}} \\
26.455 \\
0.118 \\
0.994 \\
0.05 \\
0.974 \\
-2.908\end{array}$ \\
\hline $\begin{array}{l}\text { Freundlich model } \\
\text { Plot } \\
\text { Fitted model } \\
K_{F} \\
n \\
R^{2} \\
\text { SSE } \\
\text { AIC }\end{array}$ & $\begin{array}{l}- \\
- \\
{[\mathrm{mg} / \mathrm{g}]} \\
{\left[\mathrm{mg} / \mathrm{g}\left(\mathrm{dm}^{3} / \mathrm{mg}\right)^{1 / \mathrm{n}}\right]}\end{array}$ & $\begin{array}{l}\ln \mathrm{q}_{\mathrm{e}}=\ln \mathrm{K}_{\mathrm{F}}+1 / n \ln \mathrm{C}_{\mathrm{e}}{ }^{24} \\
\ln \mathrm{q}_{\mathrm{e}} v \mathrm{~s} \cdot \ln \mathrm{C}_{\mathrm{e}} \\
\ln \mathrm{q}_{\mathrm{e}}=1.7408+0.3586 \ln \mathrm{C}_{\mathrm{e}} \\
5.702 \\
2.788 \\
0.963 \\
0.907 \\
-3.333\end{array}$ \\
\hline $\begin{array}{l}\text { Dubinin-Radushkevich model } \\
\text { Plot } \\
\text { Fitted model } \\
K_{D R} \\
E=1 / \sqrt{2} K_{D R} \\
\mathrm{q}_{\mathrm{m}} \\
R^{2} \\
S S E \\
\text { AIC }\end{array}$ & $\begin{array}{l}- \\
- \\
{\left[\mathrm{mol}^{2} / \mathrm{kJ}^{2}\right]} \\
{[\mathrm{kJ} / \mathrm{mol}]}\end{array}$ & $\begin{array}{l}\ln \mathrm{q}_{\mathrm{e}}=\ln \mathrm{q}_{\mathrm{m}}-\mathrm{K}_{\mathrm{DR}} \varepsilon^{2} 33 \\
\ln \mathrm{q}_{\mathrm{e}} v \mathrm{~s} . \varepsilon^{2} \\
\ln \mathrm{q}_{\mathrm{e}}=2.8835-2 \mathrm{E}-06 \varepsilon^{2} \\
2 \mathrm{E}-06 \\
0.5 \\
17.876 \\
0.848 \\
3.681 \\
5.069\end{array}$ \\
\hline $\begin{array}{l}\text { Temkin model } \\
\text { Plot } \\
\text { Fitted model } \\
A \\
B \\
R^{2} \\
\text { SSE } \\
\text { AIC }\end{array}$ & $\begin{array}{l}{\left[\mathrm{dm}^{3} / \mathrm{g}\right]} \\
{[\mathrm{J} / \mathrm{mol}]}\end{array}$ & $\begin{array}{l}\mathrm{q}_{\mathrm{e}}=\mathrm{B} \ln \mathrm{A}+\mathrm{Bln}_{\mathrm{e}} \mathrm{C}^{34} \\
\mathrm{q}_{\mathrm{e}} v \mathrm{~s} \cdot \ln \mathrm{C}_{\mathrm{e}} \\
\mathrm{q}_{\mathrm{e}}=5.1316 \ln \mathrm{C}_{\mathrm{e}}+2.1246 \\
1.5129 \\
5.1316 \\
0.992 \\
0.485 \\
-3.664\end{array}$ \\
\hline $\begin{array}{l}\text { Redlich-Peterson } \\
\text { Plot }\end{array}$ & & 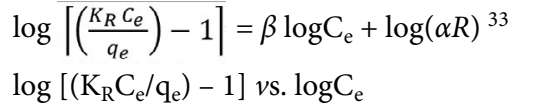 \\
\hline Fitted model & & $\log \left[\left(\frac{K_{R} C_{e}}{q_{e}}\right)-1\right]=1.1454 \log \mathrm{Ce}-1.1229$ \\
\hline $\begin{array}{l}K_{R}=q_{\max } k_{L} \\
\beta \\
\alpha R \\
R^{2} \\
S S E \\
A I C\end{array}$ & {$\left[\mathrm{dm}^{3} / \mathrm{g}\right]$} & $\begin{array}{l}3.1217 \\
1.1454 \\
13.27 \\
0.987 \\
14.811 \\
23.422\end{array}$ \\
\hline
\end{tabular}

on a homogenous absorbing surface. The theoretical maximum of adsorption capacity computed by the Langmuir model was found to be $26.455 \mathrm{mg} / \mathrm{g}$. In a study conducted by Kannan and Murugavel, ${ }^{7}$ commercial activated carbon and cashew nut shell carbon were utilized for the removal of AV 17 dye at a concentration of $140 \mathrm{mg} / \mathrm{L}$ with adsorption, and $\mathrm{q}_{\max }$ was obtained to be 72.01 and $1.975 \mathrm{mg} / \mathrm{g}$, respectively.
Furthermore, the adsorption of AV 17 on the AAPS by utilizing a dimensionless parameter $\left(R_{L}\right)$ that was derived from the Langmuir equation was also evaluated. The $R_{L}$ value shows that the nature of adsorption is bad in case of $R_{L}>1$, linear in case of $R_{L}=1$, good in case of $0<R_{L}<1$ and irreversible in case of $R_{L}=0 .{ }^{35}$ In Table $5, R_{L}$ (the separation factor) is $0<R_{L}<1$ indicating that adsorption was good. The amount of " $n$ " in the Freundlich equation was 
also shown in Table 5. The $n$ value demonstrates the nonlinearity degree between solution concentration and adsorption as presented below: in case of $n=1$, the adsorption process is linear; in case of $n<1$, adsorption represents a chemical process; in case of $\mathrm{n}>1$, adsorption represents a physical process. The case of $n>1$ is the most frequently encountered and may be caused by a distribution of surface sites or any factor that leads to decreased interaction between adsorbent and adsorbate with an increase in surface density, and the $n$ values in the interval between $1-10$ indicate favorable adsorption. ${ }^{36}$ In the current research, the value of $n$ in the Freundlich equation was determined to be 2.788 , which suggests the physical adsorption of AV 17 onto AAPS. Furthermore, it confirms that AAPS is appropriate as an adsorbent for AV 17 removal.

The $E$ value for the $\mathrm{D}-\mathrm{R}$ isotherm is very beneficial for predicting the adsorption type. The values below $8 \mathrm{~kJ} /$ mol demonstrate that adsorption is a physical process, and the $E$ value in the range of $8-16 \mathrm{~kJ} / \mathrm{mol}$ demonstrates that adsorption is caused by the exchange of ions. ${ }^{37}$ In this research, $E$ was found to be 0.5 , so the sorption mechanism was physical.

It is possible to implement the R-P isotherm in homogenous as well as heterogeneous systems. ${ }^{38}$ There are two restricting behaviors; the Langmuir form for $\beta \geq 1$ and Henry's law for $\beta=0$. The $\beta$ value is in the range of $0-1$, which indicates favorable adsorption. ${ }^{39}$ As the exponent, $\beta$ $=1.1454$ and adsorption is in the Langmuir form.

The Temkin isotherm model estimates that a linear decrease occurs in the adsorption energy with the surface coverage because of interactions between adsorbent and adsorbate. ${ }^{40}$ Linear plots for the Temkin adsorption isotherm, considering chemisorption of an adsorbate onto the adsorbent, fit considerably well with the correlation coefficients of 0.992 (Table 5). This further defends the idea that the adsorption of AV 17 dye onto AAPS represents chemisorption. The Temkin model represents a suitable model for the chemical adsorption on the basis of powerful electrostatic interaction occurring between positive and negative charges. ${ }^{41}$

As a result of the evaluation of the coefficients obtained for the isotherms (Table 5), the adsorption process conformed to the Langmuir and Temkin isotherms, so that the physical and chemical adsorption mechanisms were applied together, and since chemical adsorption reached the boundary zone in the adsorption of AV 17 dye at the selected concentration of $160 \mathrm{mg} / \mathrm{L}$ by AAPS, adsorption was observed to be affected by both mechanisms.

\section{2. 5. Impact of Temperature}

The sorption of AV 17 by AAPS was studied depending on temperature and dye concentration. The research was conducted in the concentration range of $40-400 \mathrm{mg} / \mathrm{L}$ at 3 different temperatures, being 303-313-323 K. Fig. 11

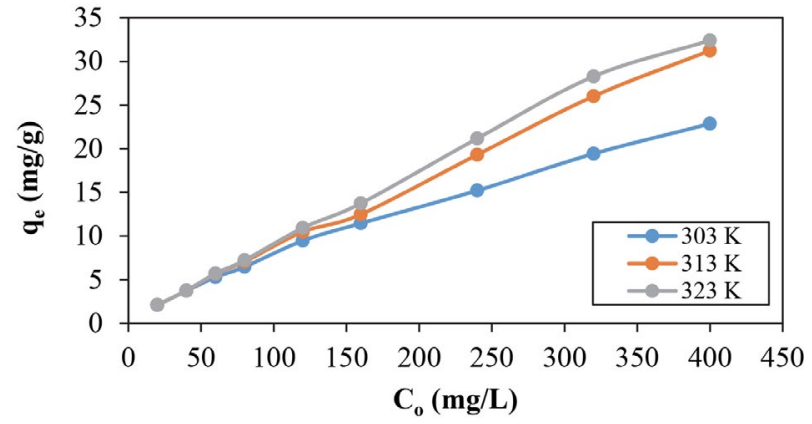

Fig. 11. Impact of temperature on the adsorption of Acid Violet 17 onto AAPS.

shows the sorption capacities obtained at different temperatures. The adsorption capacity of AAPS did not change significantly with increasing temperature at a low dye concentration $(\leq 160 \mathrm{mg} / \mathrm{L})$. However, at dye concentrations above $160 \mathrm{mg} / \mathrm{L}$, the increase in temperature caused an increase in adsorption capacity. Probably due to increased mobility of ions at a high concentration and high temperature, the diffusion of dyes into pores increased. Furthermore, the increased adsorption capacity of AAPS with temperature increase may have contributed to the adsorbent surface activation. Therefore, the process was understood to be endothermic and spontaneous, especially at high concentrations. Moreover, there is not a very significant difference between 313 and $323 \mathrm{~K}$. Thus, the adsorption of AV 17 by AAPS appears to be more effective in the mesophilic temperature range.

\section{2. 5. 1. Thermodynamic Parameters}

The equations presented below were used to determine the thermodynamic parameters, including a change in standard free energy $\left(\Delta \mathrm{G}^{\circ}\right)$, enthalpy $\left(\Delta \mathrm{H}^{\circ}\right)$, and entropy $\left(\Delta S^{\circ}\right)$ of adsorption:

$$
\begin{aligned}
& \Delta G^{\circ}=-R T \ln K_{c} \\
& \mathrm{~K}_{\mathrm{c}}=\mathrm{q}_{\mathrm{e}} / \mathrm{C}_{\mathrm{e}} \\
& \Delta G^{\circ}=\Delta H^{\circ}-T \Delta S^{\circ} \\
& \ln K_{c}=\frac{\Delta S^{o}}{R}-\frac{\Delta H^{o}}{R T}
\end{aligned}
$$

where $\mathrm{K}_{\mathrm{c}}$ represents the distribution coefficient of the adsorbate, $\mathrm{q}_{\mathrm{e}}$ and $\mathrm{C}_{\mathrm{e}}$ represent the equilibrium dye concentration on AAPS $(\mathrm{mg} / \mathrm{g})$ and in the solution $(\mathrm{mg} / \mathrm{L})$, respectively. $\mathrm{R}$ denotes the universal gas constant $(8.314 \mathrm{~J} /$ $\mathrm{mol} \mathrm{K}$ ), and $\mathrm{T}$ denotes the temperature $(\mathrm{K})$. It is possible to compute $\Delta \mathrm{H}^{\circ}$ and $\Delta \mathrm{S}^{\circ}$ parameters from the slope and intercept of the plot $\ln \mathrm{K}_{\mathrm{c}}$ vs. $1 / \mathrm{T}$, respectively (Fig. 12), and the findings are presented in Table 6.

The positive values of $\Delta \mathrm{H}^{\circ}$ indicated the endothermic nature of adsorption. ${ }^{2}$ The enthalpy $\left(\Delta \mathrm{H}^{\circ}\right)$ values above $40 \mathrm{~kJ} / \mathrm{mol}$ for $>160 \mathrm{mg} / \mathrm{L}$ dye concentration indicat- 


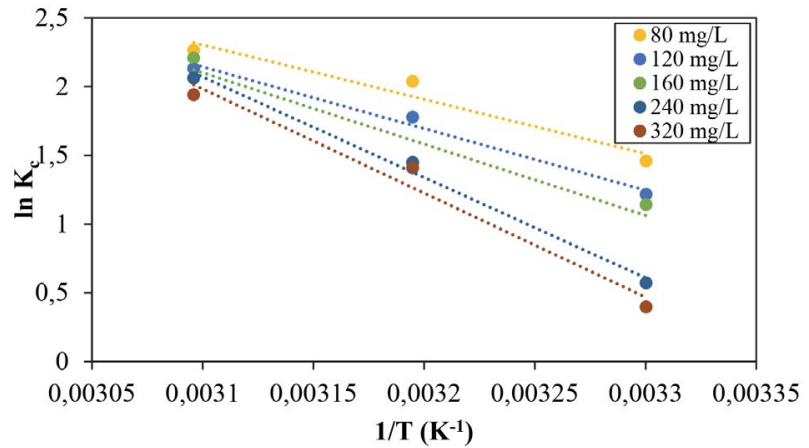

Fig. 12. The estimation of thermodynamic parameters.

ed that the adsorption of AV 17 by AAPS was chemisorption. Furthermore, the positive $\Delta S^{\circ}$ value demonstrates that an increase occurred in the degrees of freedom at the solid-liquid interface in the course of adsorption. Positive $\Delta \mathrm{S}^{\circ}$ values also suggested an increase in the randomness and affinity of AV 17 dye toward the AAPS adsorbent. ${ }^{42}$ Therefore, adsorption is favored on AV 17. More negative values of $\Delta \mathrm{G}^{\circ}$ were determined at increased temperatures, which indicates that adsorption is feasible and more spontaneous under natural conditions at higher temperatures. ${ }^{43}$

Table 6. Thermodynamic parameters.

\begin{tabular}{cccccc}
\hline $\begin{array}{c}\mathrm{C}_{\mathbf{o}} \\
(\mathbf{m g} / \mathbf{L})\end{array}$ & $\mathbf{3 0 3 K}$ & $\mathbf{3 1 3 K}$ & $\mathbf{3 2 3 K}$ & $(\mathbf{k J} / \mathbf{m o l . K})$ & $(\mathbf{k J} / \mathbf{m o l})$ \\
\hline 80 & -3.673 & -5.302 & -6.081 & 0.121 & 32.956 \\
120 & -3.063 & -4.627 & -5.723 & 0.134 & 37.325 \\
160 & -2.873 & -3.756 & -5.926 & 0.151 & 43.171 \\
240 & -1.439 & -3.769 & -5.539 & 0.206 & 60.768 \\
320 & -0.998 & -3.663 & -5.211 & 0.212 & 63.005 \\
\hline
\end{tabular}

\section{2. 6. Impact of Ionic Strength}

The effect of ionic strength on the adsorption of AV 17 onto AAPS was studied at different $\mathrm{NaCl}$, SDS and $\mathrm{CTAB}$ concentrations. Figure 13 shows that the impact of $\mathrm{NaCl}$ salt is weak as the dye removal decreased only a bit (from $93.87 \%$ to $92.06 \%$ ) with an increase in $\mathrm{NaCl}$ concentration from 0.05 to $0.25 \mathrm{~mol} / \mathrm{L}$. It is possible to attribute the slight decrease mentioned to the competition between AV 17 and chloride anions for the sorption sites. However, studies were also conducted with two different surfactants, anionic and cationic, such as sodium dodecyl sulfate (SDS) and cetyltrimethylammonium bromide (CTAB), respectively. As shown in the Fig. 13, when SDS and CTAB were added, the increase in the ionic charge of the solution caused a decrease in the adsorption percentage of the dye. These findings demonstrate that electrostatic attraction takes a significant part in the removal of AV 17. The reason for this situation can be attributed to the decrease in the affinity of dye molecules and sorption zones. In case electrostatic attraction represents the major adsorption mechanism, ionic strength has a considerable negative impact

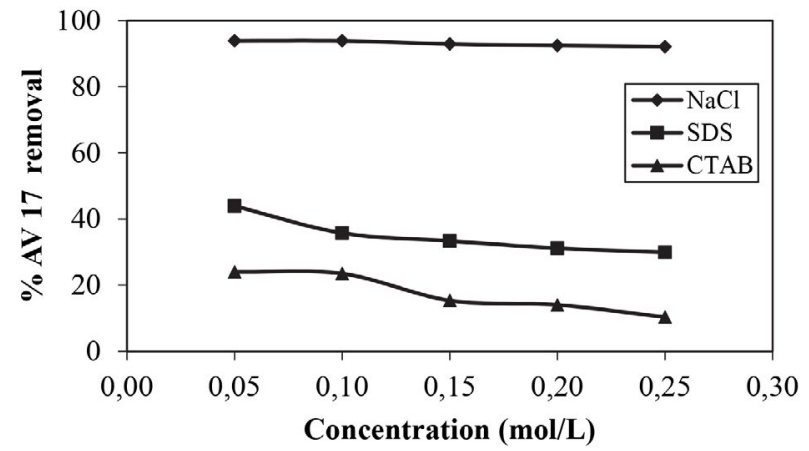

Fig. 13. Influence of ionic strength on efficiency.

on adsorption. ${ }^{21}$ The impact of $\mathrm{NaCl}$ concentration on the adsorption of acidic dyes was investigated by using brick kiln ash, and similar results were obtained. ${ }^{4}$

\section{2. 7. Desorption and Recyclability of the Adsorbent}

Desorption studies help to explain the recovery of adsorbate and adsorbent and the adsorption mechanism. The regeneration of the adsorbent makes the treatment process economical. It is, therefore, necessary to study whether the adsorbent can be reused after adsorption. 0.05-0.25 M NaCl, SDS, and CTAB solutions were utilized as a desorbing agent for the purpose of determining the desorption behavior of the AAPS. Normally, the addition of $0.1 \mathrm{~g}$ of the fresh adsorbent was performed to $75 \mathrm{~mL}$ of $60 \mathrm{mg} / \mathrm{L} \mathrm{AV} 17$ solution at $\mathrm{pH}$ 6.1, and the mixture was shaken for the period of $4 \mathrm{~h}$. Afterward, the AV 17 that was adsorbed by AAPS was separated, and a spectrophotometer was utilized to measure the residual AV 17 concentration. The dye-loaded adsorbent was washed gently using water for the removal of any dye not adsorbed and dried. The desorption process was carried out by mixing the dried adsorbent with $100 \mathrm{~mL}$ of water and ethanol as a solvent and solutions prepared at different concentrations. After the mixture was shaken for $24 \mathrm{~h}$ and $48 \mathrm{~h}$ of contact time, the spectrophotometric determination of the desorbed AV 17 concentration was performed. The results are presented in Figs. 14(a,b). The desorption efficiency was very low in desorption processes performed separately with water and ethanol. Upon examining the results, it was decided to perform regeneration with $0.2 \mathrm{M} \mathrm{NaOH}$ for 48 hours. $\mathrm{NaOH}$ selected as the regeneration agent has properties such as lower environmental load in its life cycle, less corrosive ability and cheaper chemical cost. ${ }^{44}$

Successive adsorption desorption studies were conducted in three cycles for the purpose of checking the reusability of the regenerated adsorbents. All the studies, adsorption and desorption, were carried out in a batch setup in two replicates, and the mean values were acquired. Figure 15 shows the simultaneous adsorption-desorption of the dye onto AAPS. The dye-loaded adsorbents were put in $0.2 \mathrm{M} \mathrm{NaOH}$ as the stripping solution and mixed for the 

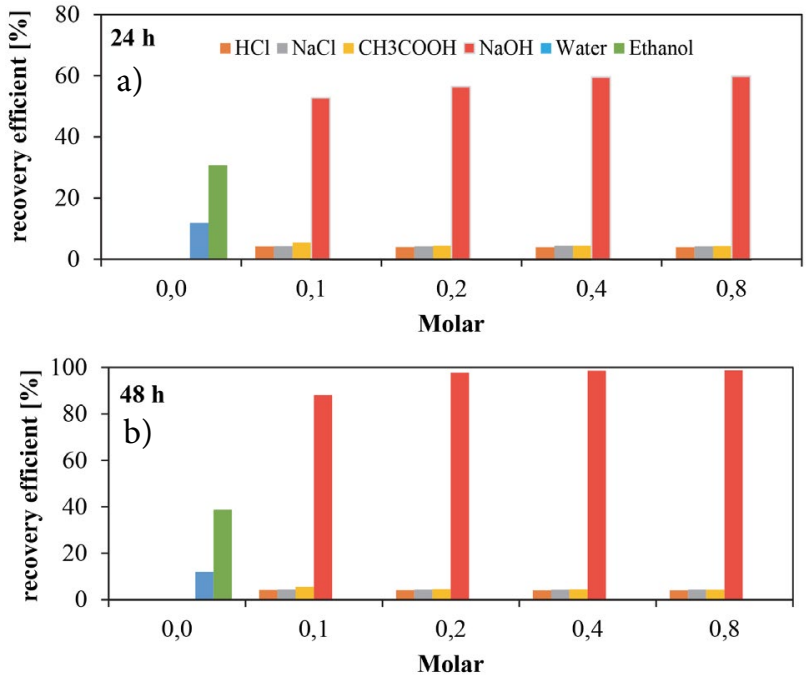

Fig. 14. Desorption of AV 17 dye from the adsorbent using different eluting agents a) $24 \mathrm{~h} \mathrm{~b}$ ) $48 \mathrm{~h}$.

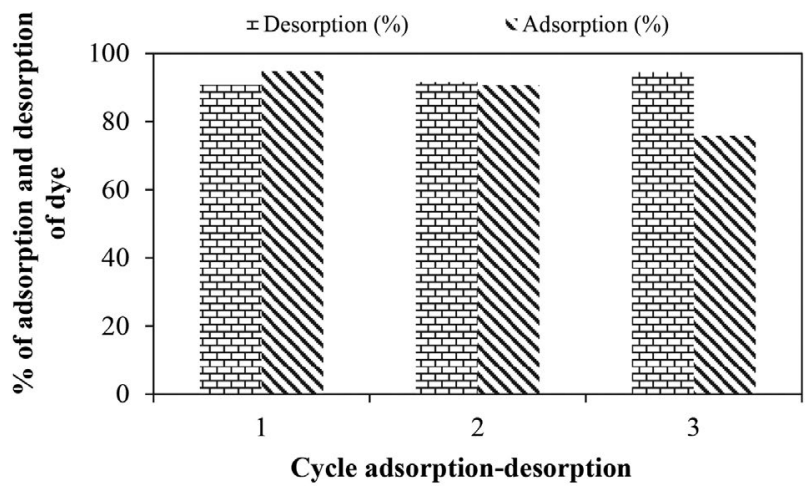

Fig. 15. Simultaneous adsorption-desorption cycles using AAPS.

period of $48 \mathrm{~h}$ at the temperature of $303 \mathrm{~K}$ to determine the final dye concentration. The percentage of desorption observed for $0.2 \mathrm{M} \mathrm{NaOH}$ was $97.73 \%$ for AAPS in the first cycle.

The AV 17 dye adsorption efficiency after three cycles of desorption decreased from 94.76 to $75.84 \%$, which represents a promising result for the possible recovery of the adsorbate and re-usage of the adsorbent. The higher desorption percentage may help in recycling the adsorbent spent and also shows that physical forces take the major part in the dye removal for the studied concentration.

\section{Conclusion}

The present study indicates that it is possible to use the activated carbon prepared from acid-activated pistachio shell efficiently in order to remove Acid Violet 17 from aqueous solution. The use of locally available pistachio shell is cost effective since it is abundantly available in Turkey at a low cost. The AIC value suggests that the Temkin isotherm described adsorption better. The behavior of adsorption was better described by the pseudo-second-order model. The enhanced sorption at higher temperature indicates an endothermic process and is spontaneous in nature, and the use of acid activated pistachio shell to remove AV 17 from industrial waste solutions at high temperatures would be more efficient. Chemical reagents could increase BET surface area, pore volume and especially surface functional groups that enhance the adsorption of material. The results showed that the AV 17 adsorption capacity was positively correlated to the BET surface area. Desorption study demonstrates that the recycling of adsorbent and adsorbate may be possible for low dye concentrations. However, the mentioned studies should not include only lab-scale batch studies, it is necessary to scale them up to pilot plants for the purpose of assessing their feasibility on a commercial scale.

\section{Acknowledgement}

We would like to kindly state that the authors are thanking and feel grateful to Sivas Cumhuriyet University, Scientific Research Project Fund for their financial support [Project number: M-661].

\section{Conflict of interest}

As the author(s), we declare that there is no conflict of interest regarding the publication of this article.

\section{References}

1. N. Thinakaran, P. Baskaralingam, M. Pulikesi, P. Panneerselvam, S. Sivanesan, J. Hazard. Mater. 2008, 151, 316-322. DOI:10.1016/j.jhazmat.2007.05.076

2. P. Vijayalakshmi, V. S. S. Bala, K. V. Thiruvengadaravi, P. Panneerselvam, M. Palanichamy, S. Sivanesan, Sep. Sci. Technol. 2011, 46, 155-163. DOI:10.1080/01496395.2010.484006

3. M. Saleem, T. Pirzada, R. Qadeer, Colloids Surf. Physicochem. Eng. Asp. 2007, 292, 246-250.

DOI:10.1016/j.colsurfa.2006.06.035

4. S. Kaur, T. P. S. Walia, R. Kaur, Online Journal of Health and Allied Sciences. 2008, 6 (3), 1-10.

5. S. N. Jain, P. R. Gogate, J. Mol. Liq. 2017, 243, 132-143. DOI:10.1016/j.molliq.2017.08.009

6. R. Sivaraj, C. Namasivayam, K. Kadirvelu, Waste Manag. 2001, 21, 105-110. DOI:10.1016/S0956-053X(00)00076-3

7. N. Kannan S. Murugavel, Glob. NEST J. 2008, 10, 395-403. DOI:10.30955/gnj.000457

8. Z. Zheng, World production and trade of pistachios: The role of the U.S. and factors affecting the export demand of U.S. pistachios, 2011, 1-67.

9. V. K. Garg, R. Gupta, A. Bala Yadav, R. Kumar, Bioresour. Technol. 2003, 89, 121-124.

DOI:10.1016/S0960-8524(03)00058-0

10. M. A. K. M. Hanafiah, W. S. W. Ngah, S. H. Zolkafly, L. C. Teong, Z. A. A. Majid, J. Environ. Sci. 2012, 24, 261-268. DOI:10.1016/S1001-0742(11)60764-X 
11. H. B. Senturk, D. Ozdes, A. Gundogdu, C. Duran, M. Soylak, J. Hazard. Mater. 2009, 172, 353-362.

DOI:10.1016/j.jhazmat.2009.07.019

12. A. Ates, A. Reitzmann, C. Hardacre, H. Yalcin, Appl. Catal., A 2011, 407, 67-75. DOI:10.1016/j.apcata.2011.08.026

13. S. Sadaf, H. N. Bhatti, J. Taiwan Inst. Chem. Eng. 2014, 45, 541-553. DOI:10.1016/j.jtice.2013.05.004

14. N. Gupta, A. K. Kushwaha, M. C. Chattopadhyaya, Arab. J. Chem. 2016, 9, 707-716. DOI:10.1016/j.arabjc.2011.07.021

15. D. H. K. Reddy, S.-M. Lee, Adv. Colloid Interface Sci. 2013, 201-202, 68-93. DOI:10.1016/j.cis.2013.10.002

16. K. S. W. Sing, D. H. Everett, R. A. W. Haul, L. Moscou, R. A. Pierotti, J. Rouquerol, T. Siemieniewska, Pure Appl. Chem. 1985, 57, 603-619.

17. D. Savova, N. Petrov, M. Yardim, E. Ekinci, T. Budinova, M. Razvigorova, V. Minkova, Carbon 2003, 41, 1897-1903. DOI:10.1016/S0008-6223(03)00179-9

18. S. B. Daffalla, H. Mukhtar, M. S. Shaharun, Int. J. Chem. Environ. Eng. 2012, 3(3), 192-200.

19. 19. A. Ma, M. Mm, J. Chromatogr. Sep. Tech. 2016, 7:4, 1-10. DOI:10.4172/2157-7064.1000329

20. R. Thenmozhi, T. Santhi, Int. J. Environ. Sci. Technol. 2015, 12, 1677-1686. DOI:10.1007/s13762-014-0531-1

21. R. Lafi, A. Hafiane, J. Taiwan Inst. Chem. Eng. 2016, 58, 424433. DOI:10.1016/j.jtice.2015.06.035

22. S. Dubey, D. Gusain, Y C. Sharma, J. Mol. Liq. 2016, 219, 1-8. DOI:10.1016/j.molliq.2016.01.021

23. F. Deniz, R. A. Kepekci, J. Mol. Liq. 2016, 219, 194-200. DOI:10.1016/j.molliq.2016.03.018

24. G. Moussavi, B. Barikbin, Chem. Eng. J. 2010, 162 (3): 893900. DOI:10.1016/j.cej.2010.06.032

25. C. Xiaoli, Z. Youcai, J. Hazard. Mater. 2006, 137 (1): 410-417. DOI:10.1016/j.jhazmat.2006.02.015

26. A. Kuleyin, F. Aydin, Environ. Prog. Sustainable Energy 2011, 30 (2): 141-151. DOI:10.1002/ep.10454

27. S. K. Nadavala, K. Swayampakula, V. M. Boddu, K. Abburi, J. Hazard. Mater. 2009, 162, 482-489.

DOI:10.1016/j.jhazmat.2008.05.070
28. I. A. W. Tan, A. L. Ahmad, B. H. Hameed, J. Hazard. Mater. 2008, 154, 337-346. DOI:10.1016/j.jhazmat.2007.10.031

29. Z. Rawajfih, N. Nsour, J. Colloid Interface Sci. 2006, 298, 3949. DOI:10.1016/j.jcis.2005.11.063

30. G. Moussavi, M. Mahmoudi, J. Hazard. Mater. 2009, 168, 806-812. DOI:10.1016/j.jhazmat.2009.02.097

31. M. I. El-Khaiary, G. F. Malash, Hydrometallurgy 2011, 105, 314-320. DOI:10.1016/j.hydromet.2010.11.005

32. I. Senturk, H. Buyukgungor, F. Geyikci, Desalination Water Treat. 2016, 57, 19529-19539. DOI:10.1080/19443994.2015.1102088

33. S. Sivakumar, P. Muthirulan, M. Meenakshi Sundaram, Arabian J. Chem. 2014, xx-xx. DOI:10.1016/j.arabjc.2014.10.028

34. N. A. Oladoja, C. O. Aboluwoye, Y. B. Oladimeji, Turkish J. Eng. Env. Sci. 2008, 32: 303-312.

35. Dada et al., IOSR J. Appl. Chem. 2012, 3, 38-45. DOI:10.9790/5736-0313845

36. M. B. Desta, J. Thermodyn. 2013, 1-6. DOI: $10.1155 / 2013 / 375830$

37. M. Ghasemi, M. Naushad, N. Ghasemi, Y. Khosravi-fard, J. Ind. Eng. Chem. 2014, 20, 2193-2199.

DOI:10.1016/j.jiec.2013.09.050

38. E. Alver, A. Ü. Metin, Chem. Eng. J. 2012, 200-202, 59-67. DOI:10.1016/j.cej.2012.06.038

39. O. Abdelwahab, Egypt. J. Aquat. Res. 2007, 33 (1): 125-143.

40. H. K. Boparai, M. Joseph, D. M. O'Carroll, J. Hazard. Mater. 2011, 186, 458-465. DOI:10.1016/j.jhazmat.2010.11.029

41. Y. Gao, Y. Li, L. Zhang, H. Huang, J. Hu, S. M. Shah, X. Su, J. Colloid Interface Sci. 2012, 368, 540-546.

DOI:10.1016/j.jcis.2011.11.015

42. S. N. Jain, P. R. Gogate, Int. J. Environ. Sci. Technol. 2017, 14, 531-542. DOI:10.1007/s13762-016-1160-7

43. V. da Silva Lacerda, J. B. López-Sotelo, A. Correa-Guimarães, S. Hernández-Navarro, M. Sánchez-Báscones, L. M. Navas-Gracia, P. Martín-Ramos, J. Martín-Gil, J. Environ. Manage. 2015, 155, 67-76. DOI:10.1016/j.jenvman.2015.03.007

44. K. Y. Foo, B. H. Hameed, Bioresour. Technol. 2012, 116, 522 525. DOI:10.1016/j.biortech.2012.03.123

\section{Povzetek}

Luščine pistacije predobdelane $\mathrm{z}$ različnimi kemijskimi spojinami smo testirali kot adsorbent za odstranjevanje barvila AV 17 iz vodnih raztopin. Maksimalno odstranitev $93.04 \%$ smo dosegli z luščinami pistacije predobdelanimi z $10 \mathrm{~N}$ $\mathrm{H}_{2} \mathrm{SO}_{4}$. Adsorbent smo okarakterizirali z metodami $\mathrm{pH}_{\mathrm{pzc}}$, FTIR, BET in SEM-EDX. Rezultati so pokazali, da je adsorpcijska kapaciteta za AV 17 pozitivno korelirana z specifično površino določeno z BET. Hitrost adsorpcije lahko najbolje opišemo s kinetiko pseudo-drugega-reda. Ravnotežne podatke adsorpcije pa lahko opišemo z Langmuirjevo ali Temkinovo izotermo. Maksimalna kapaciteta vezave določena preko opisa z Langmuirjevo izotermo bi znašala $26.455 \mathrm{mg} / \mathrm{g}$ pri koncentraciji barvila $160 \mathrm{mg} / \mathrm{L}$. Termodinamska analiza je pokazala, da je adsorpcija endotermna. $\mathrm{Z}$ uporabo 0.2 $\mathrm{M} \mathrm{NaOH}$ smo v prvem ciklu dosegli 97.33 \% desorpcijo, kar je pomembno v primeru ekonomske uporabe adsorbenta. Rezultati kažejo, da bi lahko bile aktivirane luščine pistacij alternativni adsorbent za odstranjevanje barvil iz odpadnih industrijskih odplak.

Except when otherwise noted, articles in this journal are published under the terms and conditions of the Creative Commons Attribution 4.0 International License 